\title{
BMJ Open What factors are critical to attracting NHS foundation doctors into specialty or core training? A discrete choice experiment
}

\author{
Gillian Marion Scanlan, ${ }^{1}$ Jennifer Cleland, ${ }^{1}$ Peter Johnston, ${ }^{2}$ Kim Walker, ${ }^{2}$ \\ Nicolas Krucien, ${ }^{3}$ Diane Skåtun, ${ }^{3}$ NHS Education for Scotland
}

To cite: Scanlan GM, Cleland J, Johnston $\mathrm{P}$, et al. What factors are critical to attracting NHS foundation doctors into specialty or core training? A discrete choice experiment. BMJ Open 2018;8:e019911. doi:10.1136/ bmjopen-2017-019911

- Prepublication history for this paper is available online. To view these files, please visit the journal online (http://dx.doi. org/10.1136/bmjopen-2017019911).

Received 3 October 2017 Revised 5 January 2018 Accepted 22 January 2018

Check for updates

${ }^{1}$ Centre for Healthcare Education Research and Innovation (CHERI), Institute of Education for Medical and Dental Sciences, School of Medicine, Dentistry and Nutrition, University of Aberdeen, Aberdeen, UK ${ }^{2} \mathrm{NHS}$ Education for Scotland, Scotland Deanery, Aberdeen, UK ${ }^{3}$ Health Economics Research Unit (HERU), School of Medicine and Dentistry, University of Aberdeen, Aberdeen, UK

Correspondence to Gillian Marion Scanlan; r01gms15@abdn.ac.uk

\section{ABSTRACT}

Objectives Multiple personal and work-related factors influence medical trainees' career decision-making. The relative value of these diverse factors is under-researched, yet this intelligence is crucially important for informing medical workforce planning and retention and recruitment policies. Our aim was to investigate the relative value of UK doctors' preferences for different training post characteristics during the time period when they either apply for specialty or core training or take time out. Methods We developed a discrete choice experiment (DCE) specifically for this population. The DCE was distributed to all Foundation Programme Year 2 (F2) doctors across Scotland as part of the National Career Destination Survey in June 2016. The main outcome measure was the monetary value of training post characteristics, based on willingness to forgo additional potential income and willingness to accept extra income for a change in each job characteristic calculated from regression coefficients.

Results 677/798F2 doctors provided usable DCE responses. Location was the most influential characteristic of a training position, followed closely by supportive culture and then working conditions. F2 doctors would need to be compensated by an additional $45.75 \%$ above potential earnings to move from a post in a desirable location to one in an undesirable location. Doctors who applied for a training post placed less value on supportive culture and excellent working conditions than those who did not apply. Male F2s valued location and a supportive culture less than female F2s.

Conclusion This is the first study focusing on the career decision-making of UK doctors at a critical careers decision-making point. Both location and specific job-related attributes are highly valued by F2 doctors when deciding their future. This intelligence can inform workforce policy to focus their efforts in terms of making training posts attractive to this group of doctors to enhance recruitment and retention.

\section{INTRODUCTION}

Accurately predicting medical workforce supply is increasingly challenging. Doctors no longer behave in time-recognised ways in
Strengths and limitations of this study

- An important strength of this study is that it surveyed all Foundation Programme Year 2 (F2) doctors in Scotland: that is, those at a critical point in medical careers decision-making (ie, the time of committing to specific specialty or core training programmes).

- Survey responses were received from $84.8 \%$ of the eligible population of F2 doctors in Scotland ( $n=798)$.

- Our sample was diverse and representative of the UK population of F2 doctors in terms of gender, graduate application rates and those who applied versus those who did not apply for training.

- Our focus was on generic 'push-pull' factors rather than specialty choice (ie, surgery or general practice). Thus, we could not investigate if there was an association between certain preferences and whether or not a respondent applied for specialty training or for particular training programmes.

terms of career decision-making, and their behaviour no longer fits with service need. ${ }^{1}$ For example, in the UK context, medical graduates are choosing not to progress through training as predicted. In 2016, nearly $50 \%$ of those graduates completing the Foundation Programme (FP; the generic two year training programme which bridges the gap between medical school and being eligible to apply for core, specialty or general practice) did not apply for core medical training or specialty training (including general practice) at the standard point in time. ${ }^{23}$ Simply put, one in two of today's medical graduates left the training pipeline at the first natural break opportunity while keeping their options open (ie, with full registration and eligibility to apply for higher training). Instead, they opted to take a break from training, often working overseas for a period of time. ${ }^{4}$ Although working overseas has always been a popular option, ${ }^{5}$ the difference nowadays is that at least one in twenty FP doctors appear 
to leave the UK workforce for good. ${ }^{6}$ Given this 'brain drain', more understanding of what is important to the career decision-making of doctors as they enter their post-FP phase is crucial in order to identify how best to enhance the attractiveness of medical training and thus ensure sufficient doctors to deliver service now and in the future. $^{7}$

There is a wide literature examining the factors influencing medical student, trainee doctor and qualified healthcare professional workplace supply and career decision-making factors. This literature highlights the influence of sociodemographic factors such as gender ${ }^{8-10}$ and the importance of financial incentives, ${ }^{11-14}$ professional and educational development, ${ }^{14}{ }^{15}$ geographical location, ${ }^{11} 1617$ work-life balance, ${ }^{18}{ }^{19}$ quality of life, ${ }^{20} 21$ flexibility, ${ }^{18} 2122$ working conditions ${ }^{17202324}$ and prior education ${ }^{25}$ in medical career decision-making. Recent studies have provided some insight into Foundation doctors' preferences specifically. This research suggests that job-related factors, such as the level of support and satisfaction throughout the Foundation Programme impact on FP doctor career decision-making. ${ }^{26-28}$ This information is important as it was previously assumed that medical careers preferences and values were formed prior to leaving medical school. ${ }^{20} 2129$ If this is not the case, it is crucial to identify the key attributes that play a crucial role in making training posts more attractive to those in the early stages of postgraduate training, as this intelligence may be used to inform interventions aimed at increasing the number of doctors staying in the training pipeline.

Senior doctors, medical trainee and senior student preferences for job characteristics ${ }^{17} 30{ }^{31}$ have progressed from relying on simple surveys ${ }^{32} 33$ to using discrete choice experiments (DCEs) to identify the relative importance medical students and trainees place on different characteristics. ${ }^{17}{ }^{30}$ However, to date, this approach has not been used specifically with FP Year 2 (F2) doctors although this is a group whose career-related decisions are crucial to the present and future delivery of care. Indeed, very little is known about the critical factors in F2 career decision-making. The original UK DCE work of Cleland and colleagues did not allow for the identification of the most important attributes that are critical for F2 doctors, while DCEs with junior doctors in other contexts have narrowly focused on specific careers preferences. ${ }^{17} 34-36$

Thus, to address this gap in the literature, we developed a new DCE (see later) to assess the importance of different factors that make training posts more, or less, attractive to F2 doctors. Our ultimate aim in doing so was to investigate the relative value of F2 doctors' preferences for different training post characteristics at the time in which they either apply for core training, specialty training or take a break.

\section{METHODS}

This study used a quantitative technique, known as a DCE, to elicit training post preferences. ${ }^{17} 37$ This technique presents respondents with a series of choices to be made between hypothetical training posts. Each post is presented as a bundle of key characteristics (such as geographical location, culture of working and learning environment, etc) where each bundle presents alternative levels of these characteristics (desirable or undesirable location, etc, see table 1). By selecting one hypothetical training post over another, respondents indicate their willingness to trade off these characteristics, and in doing so, the relative importance of the characteristics can be measured. Thus, the DCE approach can measure how willing an individual is to substitute one attribute for another $^{31}$ (eg, being very familiar with a specialty over poorer working conditions). These trade-offs can be converted into willingness-to-pay (WTP) values when a monetary attribute is included in the DCE..$^{37} 38$

\section{Context}

In the UK, medical students spend between 4-6 years at medical school. On graduation, over $98 \%$ of medical students apply for the FP. This is a generic two year training programme which bridges the gap between medical school and specialty training. FP doctors mostly undertake six four-month rotations, with regular assessments and milestones. At the end of the F1 year, trainees obtain full registration with the regulator (General Medical Council (GMC)). Satisfactory completion of F2 makes them eligible to apply for further specialty training, some of these include; core medical training, surgery and general practice. In November of their second year, during their fourth rotation, F2 doctors can apply for the next stage of their postgraduate training through a national recruitment and selection process. The specialty training programmes recognised by the GMC last between 3-8 years, and at the end of training, doctors are awarded the certificate of completion of training which allows them to work as a consultant or general practitioner (GP) in that specialty.

\section{Development of the Discrete Choice Experiment (DCE)}

Following guidelines, ${ }^{39}$ we used qualitative methods to generate the characteristics (eg, working conditions) and levels (eg, excellent, good, poor) presented within the hypothetical training posts and to ensure that both these and the language used were clear, sensible and meaningful to the respondents. We first consulted the international literature on medical labour markets and careers decision-making to identify which attributes might be relevant. However, as little of the literature was drawn from our target population of postregistration, prespecialty training doctors were needed to bridge this evidence gap to refine the content and choice of attributes. To find out more about what was important to this group, we carried out two focus groups and 21 individual interviews with Foundation doctors drawn from two 
Table 1 Characteristics of training positions and the range of possible levels presented within the choice scenarios. (Application for training posts: We would like you to consider some alternative training posts/opportunities open to you after you have completed your FY2 training. Imagine back to December 2016 when the application deadlines were for core, specialty and GP training courses and imagine that you were considering two alternatives. The two positions only differ according to the characteristics outlined in the table below. All other unmentioned characteristics are the same. Please take some time to look over these.)

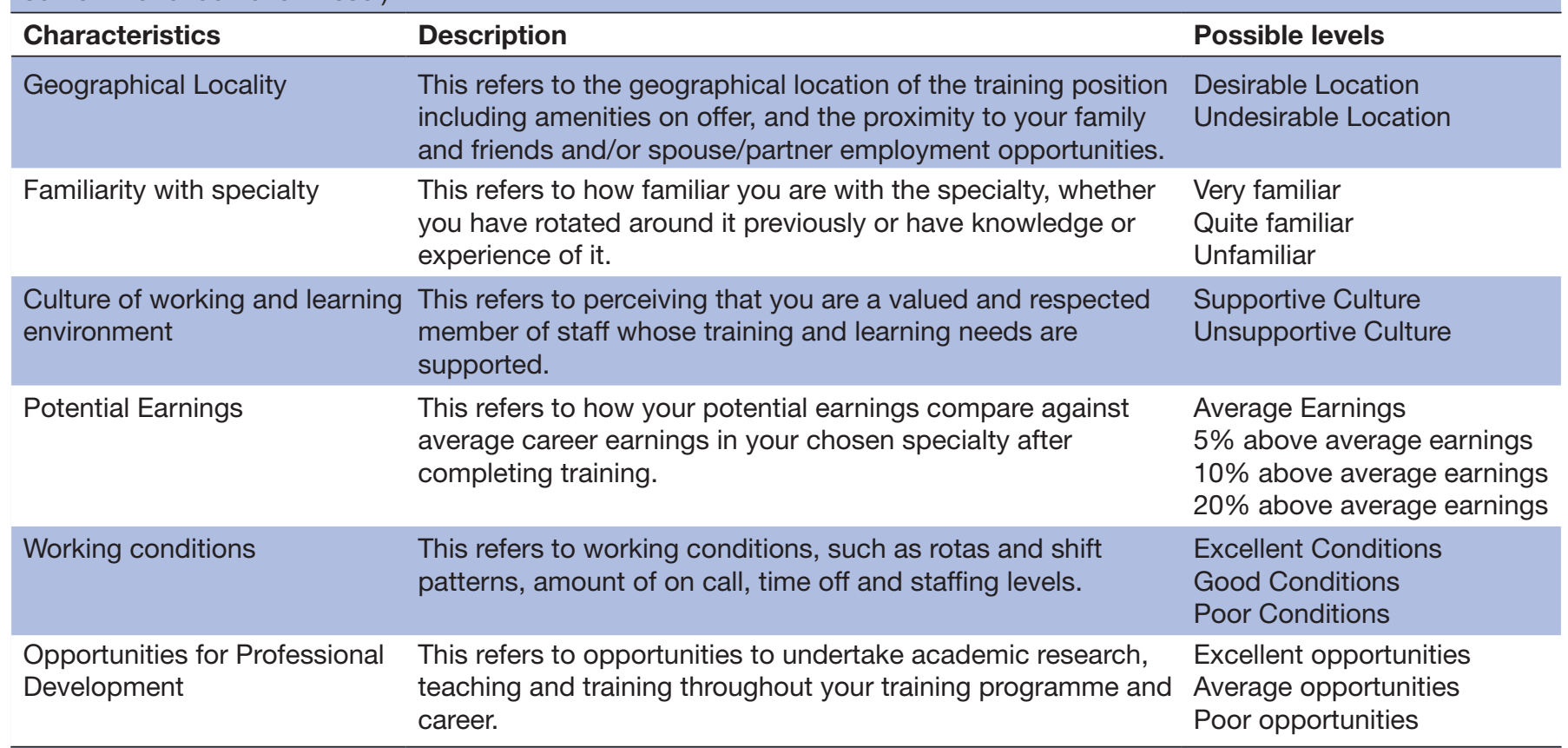

contrasting Scottish regions between December 2015 and April 2016. These regions were chosen as they are diverse in terms of size and geographical locality and because local data indicated that they attract a different groups of FP doctors in terms of home origin and medical school attended. Using a semistructured interview schedule, we gathered data about the key characteristics considered when applying for training posts.

This two-stage methodology identified five characteristics of training positions that were likely to be major drivers of F2 doctors in their medical career decision-making behaviour and specifically their progression into the specialty training phase (see table 1 ). These were the culture of the working and learning environment, opportunities in professional development and the familiarity with the specialty (see table 1 ). Two further characteristics coincided with those identified previously and used within a DCE for medical trainees in general: that is working conditions and geographical location. ${ }^{17}$ The levels attached to each of these characteristics were informed by the existing literature, the qualitative data and the expert knowledge of the research team. The resulting DCE was piloted with $31 \mathrm{~F} 2$ doctors who provided feedback on the range and wording of the attributes and levels. This piloting also allowed us to test the face validity of the DCE questionnaire. No major changes were deemed necessary based on the pilot.

Potential earnings were not identified in the qualitative work as a potential motivator of F2 doctors' decisions, but we still decided to include this characteristic in the
DCE attribute to allow for computation of willingness to pay (WTP) values. WTP values correspond to trade-offs between changes in potential earnings and the other post characteristics (eg, how large pay increase should be to compensate F2 doctors for a deterioration in working conditions). These WTP values can be used to identify the most valued characteristics (ie, those with the largest impact on F2 doctors' decisions).

The survey explained the DCE task and described each attribute and its levels before the tasks were presented. In each task, the F2s doctors were asked to choose their preferred training position between two available (see figure 1).

The training positions were presented in 13 choice sets, each containing two hypothetical training positions. These choice sets were generated through Ngene, ${ }^{40}$ a statistical software package for designing choice experiments. A D-efficient design with null priors was generated with 12 choice sets to investigate the main effects of changes in the training position's characteristics on respondents' choices. ${ }^{41}$ In addition, one choice set was repeated (task 13) to check for choice consistency (ie, whether the respondents answered consistently to a repeated choice set task). All choice sets were randomised and computed into 12 choice sets, this prevented repetition of a choice task.

\section{Sample and Data Collection}

The DCE was incorporated into the National F2 Career Destination Survey $2016^{4}$ within Scotland. This e-survey 
In this section of the survey we are interested in the factors that have influenced your career decision making in your FY2 year and what characteristics are the most important when making a decision on whether to apply for specialty training, core training or GP training programmes. This section of the survey will ask you a series of choices on what post FY2 training place you would prefer based on characteristics of training places.

Now you will be given a series of 13 choices to make that are all slightly different. For each choice you will be asked two separate questions. One will be to select which option you prefer between the 2 training positions on offer. You may not like either post but we would like you to state which one you think is better!

There are no right or wrong answers to these questions, we are just interested in your opinion!

Choice 1 of 13: Which position would you prefer?

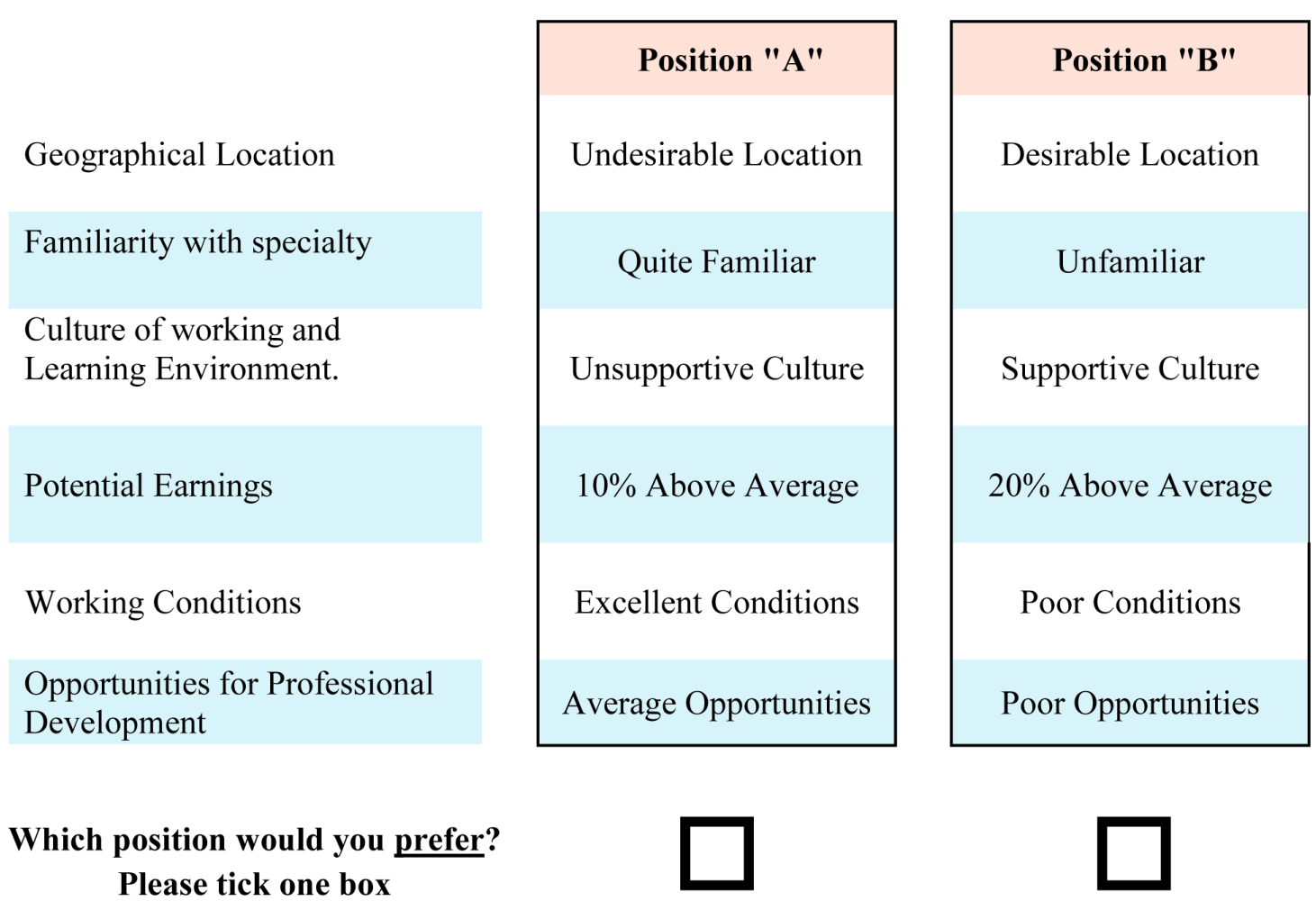

Figure 1 Characteristics of training positions and main and interaction effects based upon the multinomial logit model. 
collects data on the career destinations of F2 doctors as near as practicable to completion of their foundation training and so was considered an apt vehicle for our DCE. The Destination Survey was sent via email by the Scottish Foundation Programme director to all Scottish F2 doctors due to complete F2 in $(\mathrm{n}=798)$ in June 2016 and closed in August 2016. Two reminder emails were sent during this time. No formal sample size calculation was undertaken as we surveyed the whole population of F2 doctors in Scotland. Note that for the DCE, a minimum of only 35 respondents was needed to estimate sample preferences for job post.

\section{Preference analysis}

We modelled the probability that the training position is selected as a function of the characteristics and levels being offered within that particular choice set. This can be represented via a multinomial logit model ${ }^{42}$ with the underlying utility $\left(\mathrm{V}_{\mathrm{ntj}}\right)$ obtained through the characteristics of the training positions presented by the following: $\mathrm{V}=\mathrm{b} . \mathrm{X}+\mathrm{e}$, where $\mathrm{e}$ is an error term which is independently and identically distributed as type 1 extreme value.

$\mathrm{V}_{\mathrm{ntj}}=\alpha+\beta_{1}$ Geographical Locality: Desirable $+\beta_{2}$ Familiarity with Specialty: Very Familiar $+\beta_{3}$ Familiarity With Specialty: Quite Familiar $+\beta_{4}$ Culture of Working and Learning Environment: Supportive $+\beta_{5}$ Working Conditions: Excellent $+\beta_{6}$ Working Conditions: Good $+\beta_{7}$ Opportunities in Professional Development: Excellent $+\beta_{8}$ Opportunities in Professional Development: Average $+\beta_{9}$ Potential Earnings. (1)

The analysis of the five qualitative characteristics (ie, geographical locality, familiarity with specialty, culture of working and learning environment, working conditions and opportunities for professional development) was analysed on Stata and are entered in the model, as dummy-coded variables and their effects on respondents' choices are captured by the $\beta_{1}$ to $\beta_{8}$ coefficients, which represent F2 doctors' preferences for the training position characteristics. The parameter $\beta_{9}$ measures the influence of a 1-unit change in the earnings characteristic on respondents' choices; $\alpha$ is the model intercept. For the $\beta$ parameters, a positive estimate would indicate that an increase in the corresponding characteristic would make the job position more desirable and thus more likely to be selected by the trainees. For example, a positive estimate for $\beta_{1}$ would indicate that a shift from 'undesirable' to 'desirable' geographical location makes a training position more attractive. To locate these preference estimates on a more meaningful (or easier to interpret) scale, we compute WTP values as the ratio of preferences for each training position characteristic $\left(\beta_{1}: \beta_{8}\right)$ and potential earnings $\beta_{9}$. We used the delta approach on Stata to calculate the WTP CIs.These WTP values indicate how much the respondents would be willing to pay to improve the job characteristic (or should be compensated for a deterioration in the characteristic) (eg, how much financial income would need to be offered to compensate a trainee for a position offering an 'undesirable' location rather than a 'desirable' location). This in turn allows us to directly state the relative importance of the characteristics in the career decision-making.

\section{Preferences heterogeneity analysis}

The analysis above provides an estimate of the preferences for the average respondent within our sample. We therefore further explored whether preferences for training post characteristics vary by specific personal characteristics. Following the literature on career decision-making of junior doctors, we considered the impact of the following variables:

- Graduate Entrant on entering Medical School (Graduate VS Non-Graduate) ${ }^{25}$

- Gender (Male VS Female) $)^{8-10}$

- Country of Origin (Scotland, Rest of the World VS Rest of the UK (R/UK) $)^{1618}$

- Application for Further Training (Application Made VS No Application). ${ }^{1-6}$

To assess the variability in F2 choices, we included interaction terms of these personal characteristics with the training post characteristics. Given the positive signs on the main effects, a statistically significant interaction effect (along with its accompanying sign) will indicate whether that particular personal characteristic is associated with an increased (positive sign) or reduced (negative sign) strength of preference for the training post characteristic. However, this strategy would lead to a model with a relatively large number of parameters (ie, each of the nine preference parameters $(\beta)$ can be interacted with the four personal characteristics parameters, thus, leading to 36 interaction effects for a total of 46 model parameters). Thus, for ease of reporting and interpretation, we used a backward stepwise regression. This approach allowed us to start a model with all relevant variables of interest. In the next stage, the least significant variable was removed from the model using a significance level of 20\% (P value $<0.2$ ). This approach then applied the same rule to smaller models until all remaining variables were statistically significant. Thus, this method allowed us to identify the most relevant interaction effects and allowed for a more parsimonious choice model. And in the final conditional logistic regression model analysis, all personal characteristics with a non-significant level of $20 \%$ were removed.

\section{RESULTS}

The DCE was answered by $677 / 798 \mathrm{~F} 2$ doctors, giving an $84.8 \%$ response rate. Of these, $58.6 \%(n=397)$ were female, $40 \%(\mathrm{n}=271)$ male, with nine not indicating their gender. $74.6 \% \quad(\mathrm{n}=505)$ had graduated from medical school in Scotland, 20.8\% ( $\mathrm{n}=141)$ graduated elsewhere in the UK and $4.1 \% \quad(\mathrm{n}=28)$ graduated outside the UK. Three participants did not indicate where they graduated and were classified as missing data. $60.3 \%(n=408)$ were Scottish born, 24.8\% ( $\mathrm{n}=168)$ born elsewhere in the UK 
and the others from outside the UK $(14.9 \%(\mathrm{n}=101))$. $78.6 \%$ ( $\mathrm{n}=532$ ) had gone to medical school as undergraduates and $21.4 \%(\mathrm{n}=145)$ as graduate entrants. $54.7 \%$ $(\mathrm{n}=370)$ applied for specialty/core/GP training and $45.3 \%(n=307)$ did not apply for any training.

We removed six respondents because of issues on DCE data. One trainee did not complete the DCE questions, five trainees answered serially for each question (eg, they systematically answered choice 1 (or choice 2) in the DCE tasks) or answered differently to a repeated choice task, thus, providing no information about their preferences for position characteristics. This represents an $84.1 \%$ usable response rate.

\section{Main Effect Model for Logistical Regression Analysis}

Results can be found in table 2. The statistical significance of at least one level of each characteristic indicates that all key characteristics identified in the DCE design stage played a significant role in the choice of training position. Moreover, the positive coefficients indicate that an improvement in the characteristic was associated with an increased preference for a training post. On average, F2 doctors prefer a familiar training position with a more desirable location, which offers a supportive working culture, better working conditions and opportunities for professional development.

\section{WTP analysis}

The WTP values along with their CIs are displayed in the last column of table 2. For F2s to accept a training position with an undesirable rather than a desirable geographical location, the expected potential earnings should be increased by $45.74 \%$. This is the largest estimated WTP value, thus, indicating that a move from a desirable to an undesirable location would be the main driver of F2 doctors' choices.

Additionally, supportive culture was also found to be highly valued by F2 trainees. The respondents valued the move from a supportive working environment at $40.02 \%$ above-average expected earnings. Thus, a training post that offers an unsupportive culture for trainee doctors must offer a compensation of just over $40 \%$ above-average potential earnings before it will be considered attractive training.

The working conditions attribute was also highly valued by F2 doctors who valued the move from excellent to poor working conditions as equivalent to $38.54 \%$ of their annual potential income. However, within this attribute, the move from good working conditions to poor working conditions provides the higher value (equivalent to $29 \%$ of their annual potential income). The additional move from good to excellent working conditions only provided the equivalent of an additional 9.5\% increase in annual potential income.

Furthermore, F2s valued a move from a training post with average opportunities in continuing professional development (CPD) to a training post that offered excellent CPD more highly than a move from poor

\begin{tabular}{|c|c|c|}
\hline Job characteristic & MLE (SE) & WTP $(95 \% \mathrm{Cl})$ \\
\hline \multicolumn{3}{|l|}{ 1. Model parameters } \\
\hline Constant & $0.109(0.035)^{\star \star}$ & \\
\hline $\begin{array}{l}\text { Location: } \\
\text { Desirable }\end{array}$ & $1.200(0.0402)^{\star \star \star}$ & $\begin{array}{l}-45.75 \\
(-56.1 \text { to }-35.42)\end{array}$ \\
\hline $\begin{array}{l}\text { Working Culture: } \\
\text { Supportive }\end{array}$ & $1.050(0.0432)^{\star \star \star}$ & $\begin{array}{l}-40.0 \\
(-49.1 \text { to }-31.0)\end{array}$ \\
\hline $\begin{array}{l}\text { Familiarity With } \\
\text { Specialty: Quite } \\
\text { Familiar }\end{array}$ & $0.389(0.052)^{\star \star \star}$ & $\begin{array}{l}-14.83 \\
(-18.56 \text { to }-11.09)\end{array}$ \\
\hline $\begin{array}{l}\text { Familiarity With } \\
\text { Specialty: Very } \\
\text { Familiar }\end{array}$ & $0.489(0.059)^{\star \star \star}$ & $\begin{array}{l}-18.6 \\
(-24.61 \text { to }-12.64)\end{array}$ \\
\hline $\begin{array}{l}\text { Working } \\
\text { Conditions: } \\
\text { Good }\end{array}$ & $0.762(0.055)^{\star \star \star}$ & $\begin{array}{l}-29.02 \\
(-36.23 \text { to }-21.81)\end{array}$ \\
\hline $\begin{array}{l}\text { Working } \\
\text { Conditions: } \\
\text { Excellent }\end{array}$ & $1.011(0.059)^{\star \star \star}$ & $\begin{array}{l}-38.54 \\
(-46.9 \text { to }-30.2)\end{array}$ \\
\hline $\begin{array}{l}\text { Opportunities } \\
\text { for Professional } \\
\text { Development: } \\
\text { Average }\end{array}$ & $0.336(0.044)^{\star \star *}$ & $\begin{array}{l}-12.8 \\
(-16.44 \text { to }-9.22)\end{array}$ \\
\hline $\begin{array}{l}\text { Opportunities } \\
\text { for Professional } \\
\text { Development: } \\
\text { Excellent }\end{array}$ & $0.813(0.054)^{\star \star \star}$ & $\begin{array}{l}-31.0 \\
(-38.72 \text { to }-23.26)\end{array}$ \\
\hline $\begin{array}{l}\text { Potential } \\
\text { Earnings }\end{array}$ & $0.026(0.003)^{\star \star *}$ & \\
\hline
\end{tabular}

2. Model statistics

\begin{tabular}{lc}
$\begin{array}{l}\text { Number of } \\
\text { Respondents }\end{array}$ & 671 \\
$\begin{array}{l}\text { Number of } \\
\text { Observations }\end{array}$ & 15964 \\
$\begin{array}{l}\text { Number of } \\
\text { Parameters }\end{array}$ & 10 \\
Log-likelihood & -3676.4 \\
\hline
\end{tabular}

${ }^{*} \mathrm{P}<0.05 ;{ }^{* *} \mathrm{P}<0.01 ;{ }^{* \star}{ }^{*} \mathrm{P}<0.001$.

MLE, maximum likelihood estimates; WTP, willingness-to-pay/ accept estimates as per cent of earnings.

to average CPD opportunities. The move from poor to excellent professional development was valued at $31 \%$ of average expected earnings. Whereas a move from average to poor opportunities in professional development was valued at $12.8 \%$ of average expected earnings.

Additionally, F2s valued working in a very familiar specialty more highly than a quite familiar specialty. A move from a very familiar specialty to an unfamiliar specialty would need to be compensated more than $18 \%$, with this mostly explained by the finding that a move from a quite familiar specialty to an unfamiliar one would need to be compensated by more than $14 \%$. 


\section{Preferences heterogeneity analysis}

We investigated how F2 doctors' personal characteristics may affect their training post preferences. The results are reported in table 3 . Note that the number of observations in this final model are lower than in the previous model because nine respondents with missing values on their personal characteristics had to be removed from the analysis.

Nine interaction effects reached significance at the 95\% confidence level. The results indicate that males value a desirable location and supportive culture less than female trainees as indicated by the negative signs on the relevant interaction terms. F2 doctors born outside the UK value a desirable location less than F2 doctors from the rest of the UK (excluding Scotland). Graduate entrant trainees place less value on a desirable location, supportive culture and excellent opportunities in professional development than F2 who were non-graduates on applying for medical school. F2 doctors who stated that they had applied for specialty, core or GP training placed significantly less value on a supportive culture and excellent working conditions than those who did not apply for continued training after F2. However, those who applied valued a quite familiar specialty more than those who did not.

\section{DISCUSSION}

To the best of our knowledge, this is the first study focusing solely on F2 doctors' career decision-making and the first that assesses not just the value F2 doctors place on attributes of a training post but also the relative strength of these preferences. We found that all training post attributes in the model influenced the choices of our respondents. However, one attribute stood out as being most valued: desirability of geographical location. F2 doctors were willing to trade up to $45 \%$ of their average expected earnings to have a training post which was in a desirable location (defined as offering amenities and proximity to family and friends) compared with undesirable location. While this attribute could arguably be said to have little to do with the nature of the post as such, attributes that were more directly job related were also very highly valued. For example, F2 doctors were willing to trade around $40 \%$ of their average expected earnings to have a training post with a supportive culture compared with one with an unsupportive culture and just over $38 \%$ of their average expected earnings to move from excellent working conditions to poor. These valuations were strongest between poor and good compared with good and excellent. This is in line with previous UK research that highlighted that the change most valued for medical students and trainee doctors was from poor to good working conditions. ${ }^{1730}$

We found relatively few significant interactions between F2 doctor characteristics and preferences, suggesting that, although our sample was heterogeneous in terms of gender, ethnicity, origin, graduate entrants and

\begin{tabular}{|c|c|c|c|c|}
\hline & & $\boldsymbol{\beta}$ & SE & $P$ value \\
\hline \multicolumn{5}{|l|}{ Main effects } \\
\hline Constant & - & 0.114 & 0.035 & $* *$ \\
\hline $\begin{array}{l}\text { Location } \\
\text { (Desirable) }\end{array}$ & - & 1.40 & 0.075 & $* * *$ \\
\hline $\begin{array}{l}\text { Working culture } \\
\text { (Supportive) }\end{array}$ & - & 1.271 & 0.0069 & $* * *$ \\
\hline $\begin{array}{l}\text { Familiarity with } \\
\text { specialty (Quite) }\end{array}$ & - & 0.293 & 0.071 & $\star \star \star *$ \\
\hline $\begin{array}{l}\text { Familiarity with } \\
\text { specialty (Very) }\end{array}$ & - & 0.472 & 0.076 & $\star \star *$ \\
\hline $\begin{array}{l}\text { Working } \\
\text { conditions (Good) }\end{array}$ & - & 0.840 & 0.082 & $* * *$ \\
\hline $\begin{array}{l}\text { Working } \\
\text { conditions } \\
\text { (Excellent) }\end{array}$ & - & 1.162 & 0.083 & 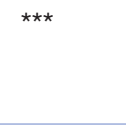 \\
\hline $\begin{array}{l}\text { Opportunities } \\
\text { for professional } \\
\text { development } \\
\text { (Average) }\end{array}$ & - & 0.361 & 0.050 & $* * *$ \\
\hline $\begin{array}{l}\text { Opportunities } \\
\text { for Professional } \\
\text { Development } \\
\text { (Excellent) }\end{array}$ & - & 0.870 & 0.061 & $\star \star *$ \\
\hline Potential earnings & - & 0.026 & 0.003 & $\star \star \star *$ \\
\hline \multicolumn{5}{|l|}{ Interaction effects } \\
\hline $\begin{array}{l}\text { Location } \\
\text { (Desirable) }\end{array}$ & Male & -0.374 & 0.059 & $\star \star \star *$ \\
\hline $\begin{array}{l}\text { Working culture } \\
\text { (Supportive) }\end{array}$ & Male & -0.20 & 0.060 & $* *$ \\
\hline $\begin{array}{l}\text { Location } \\
\text { (Desirable) }\end{array}$ & $\begin{array}{l}\text { Graduate } \\
\text { entry (yes) }\end{array}$ & -0.162 & 0.075 & * \\
\hline $\begin{array}{l}\text { Working culture } \\
\text { (Supportive) }\end{array}$ & $\begin{array}{l}\text { Graduate } \\
\text { entry (yes) }\end{array}$ & -0.168 & 0.0761 & * \\
\hline $\begin{array}{l}\text { Opportunites } \\
\text { for professional } \\
\text { development } \\
\text { (Average) }\end{array}$ & $\begin{array}{l}\text { Graduate } \\
\text { entry (yes) }\end{array}$ & -0.084 & 0.094 & \\
\hline $\begin{array}{l}\text { Opportunities } \\
\text { for professional } \\
\text { development } \\
\text { (Excellent) }\end{array}$ & $\begin{array}{l}\text { Graduate } \\
\text { entry (yes) }\end{array}$ & -0.224 & 0.106 & * \\
\hline $\begin{array}{l}\text { Familiarity with } \\
\text { specialty (Quite) }\end{array}$ & $\begin{array}{l}\text { Training } \\
\text { application } \\
\text { (yes) }\end{array}$ & 0.175 & 0.084 & * \\
\hline $\begin{array}{l}\text { Familiarity with } \\
\text { specialty (Very) }\end{array}$ & $\begin{array}{l}\text { Training } \\
\text { application } \\
\text { (yes) }\end{array}$ & 0.029 & 0.096 & \\
\hline $\begin{array}{l}\text { Working culture } \\
\text { (Supportive) }\end{array}$ & $\begin{array}{l}\text { Training } \\
\text { application } \\
\text { (yes) }\end{array}$ & -0.172 & 0.070 & * \\
\hline $\begin{array}{l}\text { Working } \\
\text { conditions (Good) }\end{array}$ & $\begin{array}{l}\text { Training } \\
\text { application } \\
\text { (yes) }\end{array}$ & -0.120 & 0.0986 & \\
\hline
\end{tabular}


Table 3 Continued

\begin{tabular}{lllll}
\hline & & $\boldsymbol{\beta}$ & SE & P value \\
\hline $\begin{array}{l}\text { Working } \\
\text { conditions } \\
\text { (Excellent) }\end{array}$ & $\begin{array}{l}\text { Training } \\
\text { application } \\
\text { (yes) }\end{array}$ & -0.240 & 0.0970 & $*$ \\
$\begin{array}{l}\text { Location } \\
\text { (Desirable) }\end{array}$ & $\begin{array}{l}\text { Home } \\
\text { country } \\
\text { (world) }\end{array}$ & -0.255 & 0.098 & $* *$ \\
& & & & \\
\end{tabular}

Model statistics

Number of

respondents

$\begin{array}{ll}\text { Number of } & 15868 \\ \text { observations }\end{array}$

Number 19

of parameters

$\begin{array}{ll}\text { Model log- } & -3613.1 \\ \text { likelihood } & \end{array}$

${ }^{*} \mathrm{P}<0.05 ;{ }^{* *} \mathrm{P}<0.01 ;{ }^{* \star} \mathrm{P}<0.001$.

non-graduate entrants to medical school, they were remarkably homogenous in terms of the factors they value in a medical career. The few differences related to F2 characteristics indicated, first, females value a desirable location and supportive working and learning culture more than their male counterparts. Differences between male and female medical students and doctors' for job-related preferences are well established. ${ }^{818}$ Typically, women have tended to prioritise work-life balance more than men. We found that factors which could loosely be related to this (desirable location, supportive environment) were more important to women-but they were also important to our male respondents just a little less so. This suggests that traditional gender differences in medicine are shifting, and previous marked differences between men and women may not be so apparent in the current generation.

Second, those who entered medicine as graduates placed less value on a desirable location and supportive culture than those who entered medical school as school leavers. Similar findings were found by Cleland et al. ${ }^{20}$ The methodology of our study means we cannot identify why this is the case, but drawing on other research, this may be associated with the need to get a job/training post without delay due to level of debt ${ }^{43}$ or greater family responsibilities. ${ }^{45}$ Or, alternatively, it could be that this group are more confident of their abilities and less reliant on support from work colleagues than their school leaver equivalents. ${ }^{46}$ Future qualitative research is needed to gain further insight.

Data shows that $50 \%$ of graduates completing the foundation programme did not apply for specialty training or core training. ${ }^{4}$ Our study shows that F2 doctors who applied for training placed significantly less value on excellent working conditions and a supportive culture than those who did not do so. Again, we do not know the reasons for this, but it merits further investigation, perhaps using qualitative methodologies to explore differences in personal characteristics such as self-efficacy, ${ }^{48}$ experience of social support from senior staff and coworkers ${ }^{48} 50$ and/or prior experience. ${ }^{10}$ Anecdotal evidence suggests that some trainees are reluctant to apply for further training until they have gained additional experience, and because once they have committed to a specialty (or training programme), career changes are difficult. This is acknowledged in the medical literature: a recent report by the GMC argues that more flexibility is needed in training to acknowledge prior learning and allow trainees to transition between specialties with more ease. ${ }^{51}$ Increasing flexibility in this way may well help recruitment, but our study shows that good working conditions and a supportive culture are also of great importance to trainees.

For those doctors who did apply for core/higher/ GP training in their F2 year, being quite familiar with a specialty was highly valued. This makes intuitive sense: committing to training can be seen as committing to a very specific medical career. Knowing a little about the specialty and the nature of the work seems a reasonable prerequisite for making such a decision. This reinforces the importance of giving medical students and trainees a wide range of experiences to encourage trainees into the breadth of specialties.

The location of a job will be known prior to accepting a training post. However, it may not be reasonable to assume that doctors will be able to determine other variables in advance. For example, they may not be able to assess the level of support in their new workplace or have a detailed knowledge of the staffing levels or career development opportunities. However, given emerging evidence indicates that experiences during the FP are influential in early career decision-making, it is perhaps timely to consider a critical evaluation of this programme.

An important strength of this study is that it surveyed all F2 doctors in Scotland: that is, those at a critical point in medical career decision-making, the traditional time of committing to training in a specific specialty. Our focus was generic 'push-pull' factors ${ }^{52}$ rather than specialty choice (eg, a preference for surgery or general practice), so we could not investigate possible links between these preferences and specialty preferences. This means that we could not compare if compensation values varied between those whose preference was to apply for one specialty rather than another and/or for a popular specialty versus a less competitive specialty. However, this generic focus allowed us to pull out differences between those who did, and did not, apply for core training or specialty training during F2. Future research could look at the association between particular preferences (eg, for work-life balance) and specialty choice.

There are approximately $8000 \mathrm{~F} 2$ doctors in the UK at any one point in time, of whom about $10 \%$ are based in Scotland. Our sample was diverse and representative of the UK population of F2 doctors in terms of gender, graduate application rates and those who applied versus 
those who did not apply for training. ${ }^{4}$ In our DCE, most graduated in Scotland and were born in Scotland; this statistic is something that may differ from the rest of the UK. However, Cleland et al ${ }^{17}$ did not find any statistical significance in the preference choices between trainees from different regions of the UK. While our opt-out clause was explicit and selected by a proportion of potential respondents, our survey escaped the usual response to an e-survey request, that of automatic deletion. The study was carried out after the national application and selection process for core, specialty or GP training was almost complete and at the completion of foundation training. Our participants had thus been thinking about their future medical career in the previous months, so the timing of our DCE was good. An interesting area for future research may be to access specialty training applications to compare the DCE responses with trainees' actual career-related behaviour.

As mentioned previously, the DCE methodology has been used in other contexts with those in the early stages of medical training. Work from Australia, using a study-specific DCE, found that doctors in their first threeyears of hospital medicine training postgraduation were willing to sacrifice up to $50 \%$ of their expected income to control their time on call (The Medicine in Australia: balancing employment and life longitudinal (MABEL) study ${ }^{34}$ ). The same programme of work also looked at how to attract GPs in Australia into rural posts, identifying the monetary value doctors placed on staying in post compared with moving to a different location. ${ }^{36}$ The only other DCE we have identified used medical students in Norway, again focusing on GP recruitment. ${ }^{53}$ This identified that the opportunity to control working hours and opportunities in professional advancement leads to a higher probability of medical students considering a move to a rural location when they were fully qualified. ${ }^{53}$ While it is difficult to compare across different DCE studies because of the bespoke nature of DCEs, there seem to be some common denominators in terms of what could broadly be termed working conditions. The arguably non-work-related factor of location may also have been important in the MABEL and Norwegian studies: we cannot tell if this was the case as in both studies, the DCE attributes focused only on work-related factors (more general factors such as location near friends and family were not incorporated). It may be that some factors are country specific but only cross-context studies will provide this insight.

This is the first study that focuses on the career decision-making of UK doctors at a critical career decision-making point, that of applying, or not, for core medical training or specialty training. We have identified that both location and specific job-related attributes are highly valued by junior doctors when making career decisions. Location is not something that can change. However, a supportive working and learning culture is something that a healthcare organisation has the power to change from within. Focusing on providing a supportive working environment is something that may help attract and retain medical trainees. In other words, meeting the needs of F2 doctors may help to strengthen the level of commitment doctors in training have towards the NHS, ${ }^{54}$ help with retention of this group of doctors and hence meet immediate and future service delivery needs.

Acknowledgements Our thanks to all those who participated in developing and piloting the DCE and completing the survey. With thanks to NHS Education for Scotland for merging the DCE onto the destination survey.

Contributors $\mathrm{JC}, \mathrm{PJ}$ and $\mathrm{KW}$ had the original idea for this project and obtained the funding for GMS's doctorate. The development of the DCE was led by GMS in collaboration with JC, PJ, KW and DS. GMS prepared the ethics application. She lead on the literature review. DS and NK supervised the analysis, which was carried out by GMS. JC, PJ and KW contributed throughout the analysis of the DCE. GMS drafted the paper guidance from DS and NK for the methods, analysis and results sections, with JC revising drafts. All authors contributed to the final paper. The study is guaranteed by the University of Aberdeen.

Funding NHS Education for Scotland funded this programme of work.

Competing interests None declared.

Patient consent Not required.

Ethics approval Ethical approval was granted for all components of this work by the College of Life Sciences and Medicine Ethical Research Board (CERB/2015/12/1269, approval granted 22 April 2016), University of Aberdeen, and the study was also approved by National Health Service Research Scotland (NHS $\mathrm{R} \& \mathrm{D})$

Provenance and peer review Not commissioned; externally peer reviewed.

Data sharing statement All available data can be obtained by contacting the corresponding author (GMS).

Open Access This is an Open Access article distributed in accordance with the Creative Commons Attribution Non Commercial (CC BY-NC 4.0) license, which permits others to distribute, remix, adapt, build upon this work non-commercially, and license their derivative works on different terms, provided the original work is properly cited and the use is non-commercial. See: http://creativecommons.org/ licenses/by-nc/4.0/

(C) Article author(s) (or their employer(s) unless otherwise stated in the text of the article) 2018. All rights reserved. No commercial use is permitted unless otherwise expressly granted.

\section{REFERENCES}

1. Arthur MB, Khapova SN, Wilderom CPM. Career success in a boundaryless career world. J Organ Behav 2005;26:177-202.

2. Rimmer A. Nearly half of trainees chose not to progress straight into specialty training in 2015. BMJ careers http://careers.bmj.com/ careers/advice/Nearly_half_of_trainees_chose_not_to_progress_ straight_to_specialty_training_in_2015 (accessed 8 Mar 2016).

3. UK foundation Programme Office. F2 career destination report. 2015 http://www.foundationprogramme.nhs.uk/pages/home/keydocs (accessed 5 Mar 2016).

4. UKFPO Career Destination Report. 2016 www. foundationprogramme.nhs.uk/download.asp?file=Careers destination_2016.pdf (accessed 8 Mar 2017).

5. Smith C, Low L. The gap between foundation years and specialty training. BMJ Careers 2012 http://careers.bmj.com/careers/advice/ view-article.html?id=20006722 (accessed 5 Nov 2016).

6. General Medical Council. Interactive reports to investigate factors that affect progression of doctors in training. $2016 \mathrm{http}: / / \mathrm{www}$. gmcuk.org/Briefing_note_Exams_and_recruitment_outcome_ reports.pdf_60060997.pdf_60086828.pdf (accessed 16 May 2016).

7. Collins A, Young R. The future of career. Cambridge: Cambridge University Press, 2000.

8. Riska E. Gender and medical careers. Maturitas 2011;68:264-7.

9. Behrend TS, Thompson LF, Meade AW, et al. Gender differences in career choice influences.industrial and organisational psychology. 22nd Annual Meeting, New York. 2007.

10. Pianosi K, Bethune C, Hurley KF. Medical student career choice: a qualitative study of fourth-year medical students at Memorial University, Newfoundland. CMAJ Open 2016;4:E147-52. 
11. Viscomi M, Larkins S, Gupta TS. Recruitment and retention of general practitioners in rural Canada and Australia: a review of the literature. Can J Rural Med 2013;18:13-23.

12. New Zealand Ministry of Health. Voluntary Bonding Scheme. 2012 http://www.health.govt.nz/our-work/health-workforce/voluntarybonding-scheme (accessed 3 Mar 2017).

13. Pathman DE, Konrad TR, King TS, et al. Outcomes of states scholarship, loan repayment, and related programs for physicians. Med Care 2004;42:560-8.

14. Rao KD, Ryan M, Shroff Z, et al. Rural clinician scarcity and job preferences of doctors and nurses in India: a discrete choice experiment. PLoS One 2013;8:e82984.

15. Takemura T, Kielmann K, Blaauw D. Job preferences among clinical officers in public sector facilities in rural Kenya: a discrete choice experiment. Hum Resour Health 2016;14:1.

16. Verma P, Ford JA, Stuart A, et al. A systematic review of strategies to recruit and retain primary care doctors. BMC Health Serv Res 2016;16:126.

17. Cleland $\mathrm{J}$, Johnston $\mathrm{P}$, Watson $\mathrm{V}$, et al. What do UK doctors in training value in a post? A discrete choice experiment. Med Educ 2016;50:189-202.

18. Gibis B, Heinz A, Jacob R, et al. The career expectations of medical students: findings of a nationwide survey in Germany. Dtsch Arztebl Int 2012;109:327-32.

19. Rich A, Viney R, Needleman S, et al. 'You can't be a person and a doctor: the work-life balance of doctors in training: a qualitative study. BMJ Open 2016;6:e013897.

20. Cleland J, Johnston PW, French FH, et al. Associations between medical school and career preferences in Year 1 medical students in Scotland. Med Educ 2012;46:473-84

21. Cleland JA, Johnston PW, Anthony M, et al. A survey of factors influencing career preference in new-entrant and exiting medical students from four UK medical schools. BMC Med Educ 2014;14:151.

22. Williams $C$, Cantillon P. A surgical career? The views of junior women doctors. Med Educ 2000;34:602-7.

23. Taylor KS, Lambert TW, Goldacre ML. Career progression and destinations, comparing men and women in the NHS: postal questionnaire survey. BMJ 2009;338:1735.

24. Boyle E, Healy D, Hill AD, et al. Career choices of today's medical students: where does surgery rank? Ir J Med Sci 2013;182:337-43.

25. Svirko E, Lambert T, Goldacre MJ. Gender, ethnicity and graduate status, and junior doctors' self-reported preparedness for clinical practice: national questionnaire surveys. $J R$ Soc Med 2014:107:66-74.

26. Smith F, Lambert TW, Goldacre MJ. Demographic characteristics of doctors who intend to follow clinical academic careers. UK: UK national surveys, 2014.

27. Brennan N, Corrigan O, Allard J, et al. The transition from medical student to junior doctor: today's experiences of tomorrow's doctors. Med Educ 2010;44:449-58.

28. Spooner S, Gibson J, Rigby D, et al. Stick or twist? Career decisionmaking during contractual uncertainty for NHS junior doctors. BMJ Open 2017;7:e013756

29. Watmough S, Taylor D, Ryland I. Using questionnaires to determine whether medical graduates career choice is determined by undergraduate or postgraduate experiences. Med Teach 2007:29:830-2.

30. Cleland JA, Johnston P, Watson V, et al. What do UK medical students value most in their careers? A discrete choice experiment. Med Educ 2017:51:839-51.

31. Ubach C, Scott A, French F, et al. What do hospital consultants value about their jobs? A discrete choice experiment. BMJ 2003;326:1432.

32. Lachish S, Goldacre MJ, Lambert T. Associations between perceived institutional support, job enjoyment, and intentions to work in the United Kingdom: national questionnaire survey of first year doctors. BMC Med Educ 2016;16:151.
33. Lambert TW, Goldacre MJ, Evans J. Views of junior doctors about their work: survey of qualifiers of 1993 and 1996 from United Kingdom medical schools. Med Educ 2000;34:348-54.

34. Sivey P, Scott A, Witt J, et al. Junior doctors preferences for specialty choice. J Health Econ 2012;31:813-23.

35. Sivey P, Scott A, Witt J, et al. Why Junior Doctors Don't Want to Become General Practitioners: A Discrete Choice Experiment from the MAYBEI Longitudinal study of Doctors. 2010. Melbourne Institute Working Paper.

36. Scott A, Witt J, Humphreys J, et al. Getting doctors into the bush: general practitioners' preferences for rural location. Soc Sci Med 2013;96:33-44.

37. Ryan M, Gerard K, Amaya-Amaya M. Using discrete choice experiments to value health and health care, Vol.11. Dordrecht, The Netherlands: Springer, 2008

38. Ryan M, Gerard K, Currie G. Using discrete choice experiments in health economics. Jones AM, ed. The Elgar Companion to Health Economics: Edward Elgar, 2012

39. Kløjgaard ME, Bech M, Søgaard R. Designing a stated choice experiment: the value of a qualitative process. Journal of Choice Modelling 2012;5:1-18.

40. Ngene 1.1.2 User Manual \& Reference Guide. The cutting edge in experimental design. 2014.

41. Reed Johnson F, Lancsar E, Marshall D, et al. Constructing experimental designs for discrete-choice experiments: report of the ISPOR Conjoint Analysis Experimental Design Good Research Practices Task Force. Value Health 2013;16:3-13.

42. McFadden D. "Conditional logit analysis of qualitative choice behavior.". Frontier in econometrics. New York: Academic Press, 1974:105-42.

43. BMA. First year medical students finance survey. $2016 \mathrm{https} / / \mathrm{ww}$ w.bma.org.uk/-/media/files/pdfs/working\%20for\%20change/shapi ng\%20healthcare/firstyearstudentfinancereport2012and2013.pdf?la= en(accessed 8 Mar 2016).

44. Grayson MS, Newton DA, Thompson LF. Payback time: the associations of debt and income with medical student career choice. Med Educ 2012;46:983-91.

45. Pyne Y, Ben-Shlomo Y. Older doctors and progression through specialty training in the UK: a cohort analysis of General Medical Council data. BMJ Open 2015;5:e005658.

46. Madden L, Mathias BD, Madden TM. In good company. The impact of perceived organizational support and positive relationships at work on turnover intentions. J Management Research Review 2015;38.

47. Lunenburg FC. Self-efficacy in the workplace: implications for motivation and performance. Inter $J$ of Management, Business, and Administration 2011:14-1.

48. Chou P. The effects of workplace social support on employee's subjective well-being. Euro J of Business and Management 2015;7.

49. Bandura A. Cultivate self-efficacy for personal and organizational effectiveness. Blackwell: Oxford, 2000.

50. Judge TA, Erez A, Bono JE, et al. Are measures of self-esteem, neuroticism, locus of control, and generalized self-efficacy indicators of a common core construct? J Pers Soc Psychol 2002;83:693-710.

51. The GMC. Adapting for the future: a plan for improving the flexibility of UK postgraduate medical training. $2017 \mathrm{https} / / /$ www.gmcuk.org/ Adapting_for_the_future__a_plan_for_improving_the_flexibility of UK postgraduate medical training_FINAL.pdf 69842348.pdf (accessed 25 Sep 2017)

52. Castles S, Miller MJ. The age of migration: international population movements in the Modern world. 4th edn. New York, NY: Guilford, 2009.

53. Holte $\mathrm{JH}$, Kjaer $\mathrm{T}$, Abelsen $\mathrm{B}$, et al. The impact of pecuniary and nonpecuniary incentives for attracting young doctors to rural general practice. Soc Sci Med 2015;128:1-9.

54. Eisenberger R, Stinglhamber F, Vandenberghe C, et al. Perceived supervisor support: contributions to perceived organizational support and employee retention. J Appl Psychol 2002;87:565-73. 